\title{
MORFO-ANATOMIA DO FRUTO E SEMENTE DE AMARELINHO (Tecoma stans (L.) Kunth - BIGNONIACEAE)
}

\author{
LAÉRCIO RIBEIRO RENÓ ${ }^{1}$, ISMAR SEBASTIÃO MOSCHETA ${ }^{2}$, ALESSANDRO DE LUCCAE BRACCINI ${ }^{3}$
}

\begin{abstract}
RESUMO - O conhecimento restrito sobre a biologia da espécie Tecoma stans (L.) Kunth (Bignoniaceae), conhecida por amarelinho e a importância que a mesma vem adquirindo, principalmente, por sua característica invasora, motivaram o presente trabalho. Aspectos anatômicos do fruto e semente podem ser usados em taxonomia, bem como em estudos relacionados à ecologia da espécie. O objetivo foi descrever e ilustrar a morfo-anatomia do fruto e das sementes de amarelinho. Frutos de diferentes plantas foram coletados, aleatoriamente, nos municípios de Jacarezinho e Maringá, Norte do Estado do Paraná. Foram confeccionadas lâminas permanentes e semipermanentes. A análise morfológica e anatômica permitiu as seguintes observações: fruto seco deiscente do tipo cápsula loculicida; ovário bicarpelar, bilocular com um septo mediano longitudinal e óvulos anátropos unitegumentados; linha de deiscência presente desde o início do desenvolvimento do fruto, quando a camada contínua de fibras é interrompida por uma faixa de células parenquimáticas; semente alada, exalbuminosa, com envoltório coriáceo que reveste o embrião. O embrião é reto, com eixo hipocótilo-radicular curto e plúmula inconspícua. A ala da semente é membranosa e hialina.
\end{abstract}

Termos para indexação: Planta invasora, Stenolobium stans (L.) Seem.

\section{MORPHOLOGY AND ANATOMY OF THE FRUIT AND SEED OF YELLOW TRUMPET FLOWER (Tecoma stans (L.) Kunth-BIGNONIACEAE)}

\begin{abstract}
The little knowledge on the biology of the species Tecoma stans (L.) Kunth (Bignoniaceae), known by its yellow trumpet flower and the importance that the same is acquiring mainly because of its aggressive characteristic have motivated the present work. Anatomical aspects of the fruit and seed can be used in taxonomy, as well as in studies related to the ecology of the species. The objective was to describe and to illustrate the morphology and anatomy of the fruit and seeds of the trumpet flower. Fruits from different plants were collected in the municipal districts of Jacarezinho and Maringá, North of the State of Paraná. Permanent and semipermanent slides were made. The morphological and anatomical analyses allowed the following observations: dry fruit, dehiscent, of the loculicidal capsule type; 2-carpel and 2-locular ovary with a longitudinal medium septa and anatropous and unitegmy ovules; line of dehiscence present since the beginning of the fruit development, when the continuous layer of fibers is interrupted by a strip of parenchyma cells; winged seed, not albuminous, with coriaceous wrapper that covers the embryo. This is straight, with short hypocotyl-radicular axis and no evident plumule. The wing of the seed is membranous and hyaline.
\end{abstract}

Index terms: weed plant, Stenolobium stans (L.) Seem.

\footnotetext{
1 Submetido em 08/08/2006. Aceito para publicação em 06/03/2007. Parte da Tese de Doutorado do primeiro autor apresentada a Universidade Estadual de Maringá (UEM), laercioreno@ibest.com.br

${ }^{2}$ Biólogo, Dr., Professor Associado, Departamento de Biologia, UEM, ismosqueta@uem.br

${ }^{3}$ Eng. Agro ${ }^{\circ}$, Dr., Professor Associado, Departamento de Agronomia, UEM, abraccini@uol.com.br
} 


\section{INTRODUÇÃO}

A espécie Tecoma stans (L.) Kunth, popularmente conhecida por amarelinho, no estado do Paraná, pertence à família Bignoniaceae (Joly, 2002). É uma espécie exótica, originária da região árida compreendida entre o Norte do México e os estados americanos do Texas, Arizona e Novo México. Citada como invasora na Nicarágua, Indonésia, África do Sul, Argentina, Polinésia e Brasil (Kranz e Passini, 1997; Bredow et al., 2004). Foi introduzida no Brasil como espécie ornamental.

Em decorrência das características excepcionais de reprodução sexuada e assexuada, tornou-se uma espécie invasora, provocando a redução da capacidade de produção das pastagens (Kranz e Passini, 1997; Lorenzi, 2000). Encontra-se disseminada na maioria dos estados brasileiros, causando problemas de ordem econômica e ambiental por deslocar espécies nativas, principalmente no Norte do Paraná e na Serra Gaúcha, no Estado do Rio Grande do Sul (Bredow et al., 2004).

No Estado do Paraná, aparece espontaneamente em mais de 100 municípios, principalmente nas regiões Norte e Oeste, onde ocupa área de mais de 80.000ha e em mais de 15.000ha domina totalmente o ambiente. É facilmente encontrada em margens de estradas, matas ciliares, terrenos baldios, áreas pedregosas e pastagens degradadas (Kranz, 2004).

Apresenta crescimento vigoroso e rápido com intensa produção de sementes, além de eficiente brotação caulinar (Kranz e Passini, 1997) e radical, através de raízes gemíferas (Renó, 2002).

A Secretaria de Estado da Agricultura e do Abastecimento (SEAB), considerando que o Instituto Agronômico do Paraná (IAPAR) classifica T. stans como uma planta invasora bastante agressiva, principalmente em áreas de pastagens permanentes, através da Resolução $\mathrm{n}^{\circ}$. 151/97, proíbe no Estado a entrada, o plantio, o transporte, a produção e o comércio de mudas, sementes, pedaços de caules e raízes (Paraná, 1997).

Visando subsidiar estratégias de assistência técnica e extensão rural para o controle, convivência, manejo e recuperação de áreas degradadas, este trabalho teve por objetivo estudar a morfologia e a anatomia do fruto e da semente em desenvolvimento.

\section{MATERIAL E MÉTODOS}

Botões florais, frutos em diferentes fases de desenvolvimento e sementes de Tecoma stans oriundos de plantas com características invasoras foram coletados aleatoriamente nos municípios de Maringá e Jacarezinho, no Noroeste e Norte Pioneiro do Estado do Paraná, respectivamente.

Cortes anatômicos do material coletado (botões florais, frutos e sementes) foram realizados a mão livre em material fresco, diafanizado por três minutos com hipoclorito de sódio, corados com azul de astra e safranina (Kraus e Arduin, 1997), montados em lâminas semi-permanentes com gelatina glicerinada.

Para a confecção de laminário permanente, as secções obtidas com auxílio de micrótomo rotatório no material emblocado em parafina e previamente submetido à bomba de vácuo, desidratado em série alcoólica-etílica e posteriormente corado com hematoxilina e safranina (Dnyansagar, 1958) e montadas lâminas com permout como meio de inclusão.

Os testes histoquímicos foram realizados em cortes obtidos de material fresco de frutos e sementes, feitos a mão livre e utilizado o lugol para indicativo de amido (Sass, 1951) e sudan IV para substâncias lipídicas (Cutler, 1978).

A terminologia utilizada para a descrição das estruturas externas e internas do fruto e da semente foi baseada em Barroso (1986) e Souza (2003).

Para as ilustrações, foram realizados desenhos obtidos através de estereomicroscópio Leica - Wild M 32 com câmara clara. Fotomicrografias foram obtidas em microscópio Olympus BX50, com aumentos de 60x, 160x, 250x e 400x e equipamento fotográfico para captura de imagem digital Leica modelo Wild MPSS 52. As imagens digitalizadas foram trabalhadas no programa Adobe Photoshop e as escalas foram feitas nas mesmas condições de ampliação.

\section{RESULTADOS E DISCUSSÃO}

\section{MORFO-ANATOMIA DO FRUTO}

Tecoma stans possui ovário súpero, ligeiramente achatado, glabro, de coloração esverdeada, medindo cerca de 4,0mm de comprimento e $1,5 \mathrm{~mm}$ de largura em sua região 
mediana; bicarpelar, formado por duas folhas carpelares fechadas que se fundem formando um septo mediano, longitudinal e bem desenvolvido, que separa o fruto em dois lóculos simétricos (Figuras 1A e 2A).

Na região basal do ovário e do fruto muito jovem de $T$. stans está presente um anel nectarífero bem desenvolvido (Figuras 1A, 1C e 1D) sugerindo a polinização entomófila da espécie. Os nectários extraflorais em T. stans estão associados as visitas freqüentes de formigas, encontradas próximas as gemas vegetativas e florais, nas flores e frutos. Os nectários representam um mecanismo anti-herbívoro das Bignoniáceas, as formigas atraídas por esses nectários contribuem para afastar os frugívoros e herbívoros (Silva, 2004). Cabe ressaltar que na epiderme do nectário de T. stans ocorrem estômatos, com função secretora de néctar (Figura 1C).

Os tricomas glandulares presentes na parede do ovário de T. stans (Figuras 1B e 1F) e no fruto muito jovem (Figuras $2 \mathrm{~A}$ e $2 \mathrm{~F}$ ), nas pétalas e pericarpo no estádio inicial de desenvolvimento do fruto jovem (Figuras 3A, 3B e 3D), não mais são encontrados nos estádios seguintes. Estes tricomas são constituídos por um pedúnculo unicelular e por uma cabeça composta por mais de dez células (Figura 3A), o que é semelhante ao observado por Machado et al. (1995) em gineceu de Zeyheria digitalis (Vell.) L. B. Sm. $\&$ Sandwith (Bignoniaceae).

O septo ovariano é formado por uma epiderme uniestratificada e parênquima percorrido por dois feixes vasculares centrais e suas ramificações que fornecem suprimento para os óvulos (Figuras 1A, 1E e 2E) e, posteriormente, às sementes (Figura 3D).

Durante o desenvolvimento do septo há um aumento do tecido parenquimático, principalmente em sua região mediana, que leva ao seu alongamento e ao afastamento das metades das placentas para a posição cada vez mais marginal, quase parietal (Figuras 3C e 3D). Diferenciação celular mais evidente ocorre na epiderme e camada parenquimática subepidérmica, que tornam-se esclerificadas nas fases finais do desenvolvimento do fruto (Figuras 4A, $4 \mathrm{E}, 4 \mathrm{~F}, 5 \mathrm{~B}, 5 \mathrm{C}$ e 5D) pelo maior espessamento das paredes, deposição de lignina e com muitas pontoações.

A placentação de $T$. stans é intermediária entre axial e parietal, o septo alonga-se na região mediana entre as hemiplacentas, empurrando-as para a periferia, em posição marginal (Figuras 2A, 2E e 3D), que é similar aquela encontrada por Costa (2003) em Tabebuia ochracea (Cham.) Standl. e, segundo Bittencourt Jr. (1995), nesta mesma espécie, as duas metades das placentas não se fundem, ocupando uma posição marginal a submarginal, indicando que houve desenvolvimento extra de tecidos nas margens dos carpelos. Observação semelhante às de Jain e Sing (1979) citado por Bittencourt Jr., (1995) em relação a placentação de Tabebuia rosea (Bertol.) A.DC. que sugeriram ainda a possibilidade de que em Bignoniaceae, a placentação axial talvez esteja em vias de se tornar parietal.

Pode-se distinguir no pericarpo do fruto muito jovem de T. stans, além do epicarpo e do endocarpo ambos uniestratificados, o mesocarpo com três camadas distintas: uma região mediana de células precursoras das fibras do esclerênquima que separa duas regiões parenquimáticas, o mesocarpo externo com células compactas, ricas em conteúdo citoplasmático e o mesocarpo interno com parênquima de aspecto esponjoso (Figura 2F).

Verifica-se, em secções transversais, que o número de camadas celulares do mesocarpo (Figura $2 \mathrm{~F}$ ) praticamente não se altera durante o desenvolvimento do pericarpo (Figura 4), fato também observado por Costa (2003) em Tabebuia ochracea. Entretanto, acentuadas divisões anticlinais ocorrem (Figura 3A) e irão definir o aspecto longitudinal e achatado do fruto.

Em T. stans, além dos feixes dorsais, ventrais e laterais, presentes no ovário, a vascularização nos estádios seguintes do fruto é acrescida por mais feixes vasculares laterais que ocorre na região interna a faixa de fibras de esclerênquima (Figura 2F). Com o desenvolvimento do fruto, feixes vasculares menores aparecem tardiamente no mesocarpo externo, completando a vascularização do pericarpo.

A linha de deiscência ou tecido de abscisão está localizada dorsiventralmente, desde a base até o ápice do pericarpo, portanto trata-se de deiscência loculicida. Isto já pode ser identificado no fruto jovem (Figura 3B). Nos estádios seguintes torna-se bem diferenciada e característica (Figura 4B). É constituída por células parenquimáticas que atravessam o pericarpo interrompendo a camada de esclerênquima. Neste tipo de fruto, a deiscência, que é um processo complexo e que envolve outras estruturas, dá-se principalmente, por ruptura neste tecido, onde as células são fracamente agrupadas, devido a alteração na tensão ocorrida durante a desidratação (Eames e MacDaniels, 1947). 

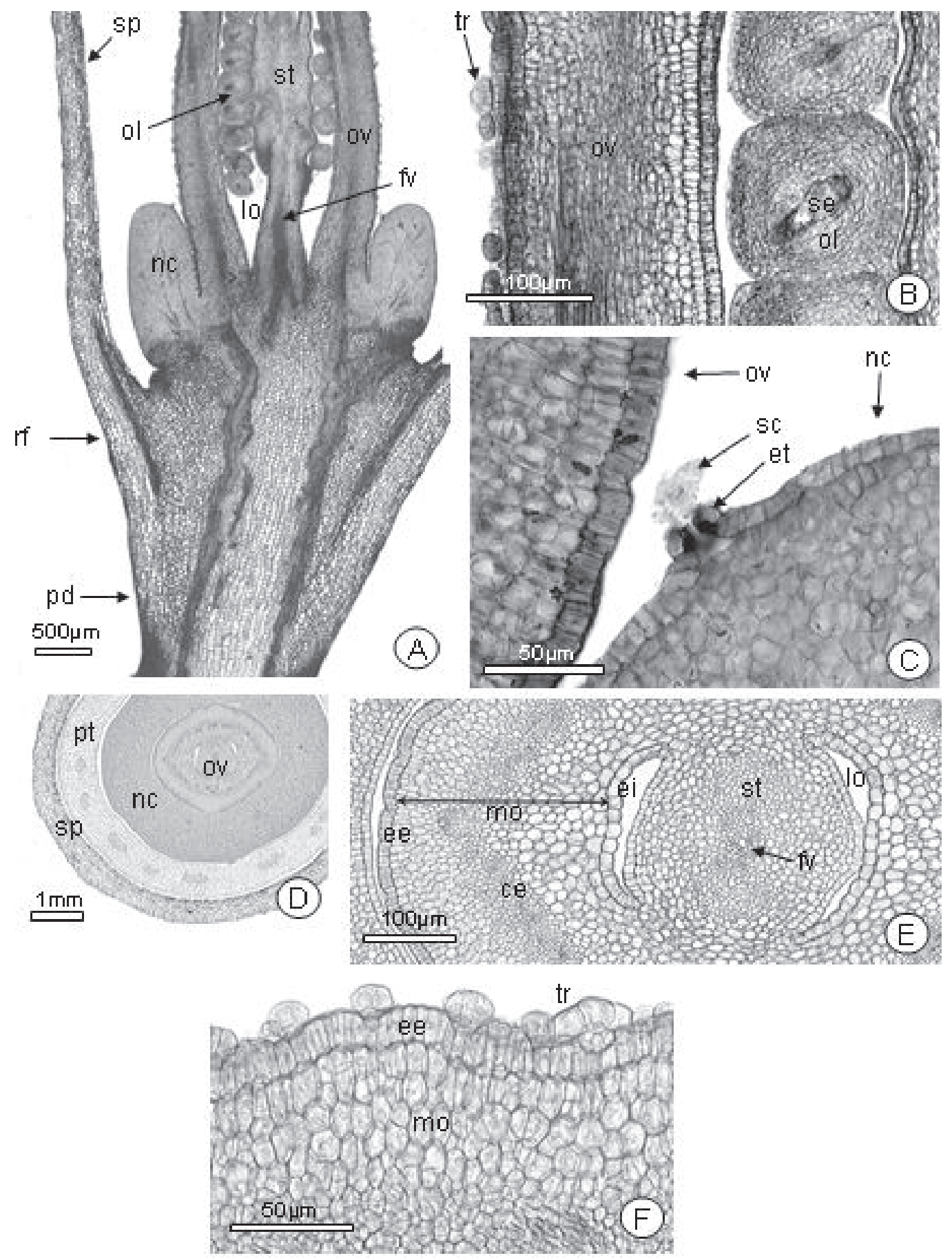

FIGURA 1 - Botăo floral de Tecoma stans: A - vista geral do bothă, desprovido de corola, em secçăo longitudinal perpendicular ao septo; B - posmenor de $1 A$ evidenciando a parede ovariana es óvulos; $\mathrm{C}$ - posmenor de $1 \mathrm{~A}$ evidenciando es t̂mab na epiderme do nectário; D - botăo em secçăo transversal na base do ovário; E - pormenor de ID evidenciando a parede ovariana e o septo com fonmato circular; F - mesofilo e epidenme extema do ovário com tricomas glandulares. Legenda: ce- céhulas precursoras do esclerênquima; ee- epiderme extema; ei- epideme intena; et- estîmab; fv- feive vascular; b- bóculo; momesofilo ovariano; nc- nectário; ol óvulo; ov- ovário; pd- pedúnculo; pt- pétala; rf- receptáculo floral; sc- secreçăo; se- saco embrionáxio; sp- sépala; st- septb; tr-tricoma glandular. 

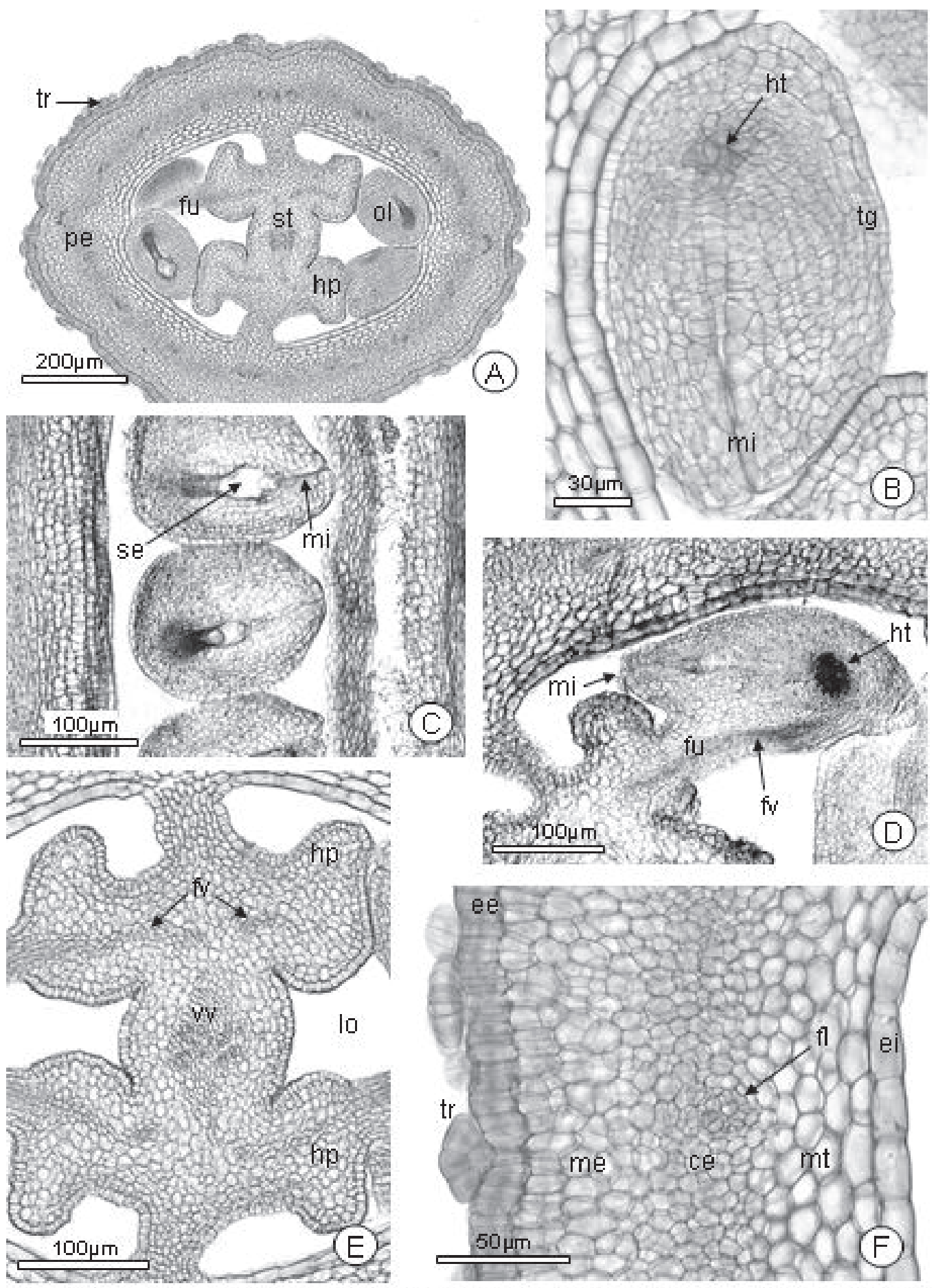

(A)
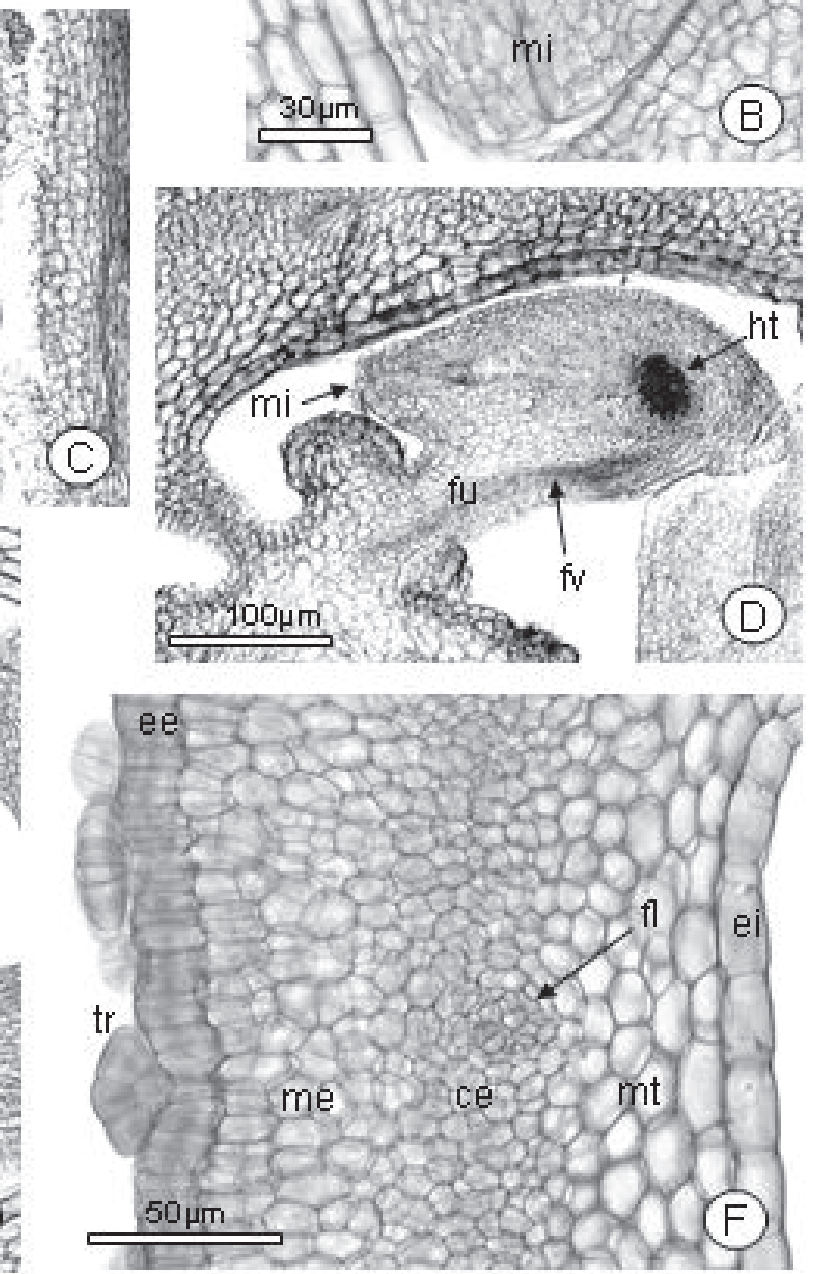

FIGURA 2 - Frub muito jovem (logo após a queda da comla) de Tecoma stans: A - vista geral em secçăo transversal mediano; B - óvulo anátropo em secçăo longitudinal; C - ovário em secçăo longitudinal com óvulos sobrepos tos; D - óvulo anátropo evidenciando a hipóstase, feixe vascular do funículo e hemiqlacenta; $\mathbf{E}$ - septo e quatro hemiqlacentas; F - parede ovariana em diferenciaçăo cehular. Legenda: cecéhulas precursoras do esclerênquima; ee epidemme extema; ei- epiderme intema; fl feive vascular lateral; fu- funículo; fv- five vascular; hp-hemiplacenta; hthipós tase; b- b́culo; me- mesocarpo extemo; mi- micrópila; mt- mesocarpo intemo; ol óvulo; pe-pericarpo; se saco embrionário; st- septb; t- tegumentb do óvulo; trtricoma glandular; w- feixe vascular ventral. 

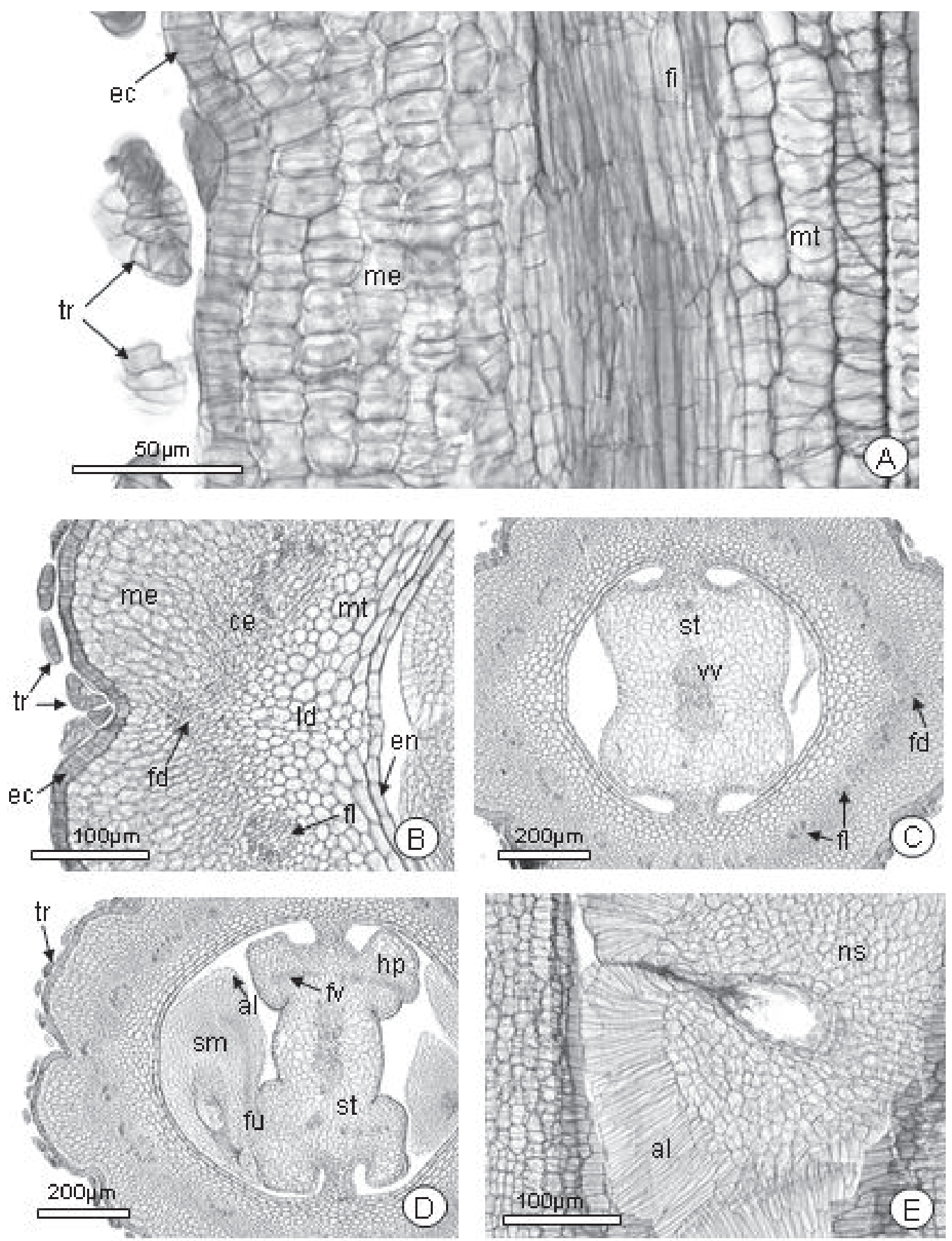

FIGURA 3 - Frub jovem (1 a $2 \mathrm{~cm}$ de compriment) de Tecoma stans: A - pericarpo jovem em secçăo longitudinal evidenciando fibras em desenvolvimento e divisöes anticlinais nas céhulas parenquimáticas do mesofilo; B - pericarpo em seç̧ăo transvessal na regiăo mediana evidenciando a linha de deiscência; C - regiăo apical em secçằ transversal; D - regiăo mediana em seç̧ăo transversal com sementes em cresciment inicial; $\mathbf{E}$ - semente com desenvolvimento inicial da ala Legenda: a- ala; ce- céhulas precusoras do esclerênquima; ec- epicarpo; enendocarpo; fd- five vascular dossal; fi- fibras; fl- five vascular lateral; fut funículo; fv- feixe vascular; hp- hemiplacenta; ld- linha de deiscência; memesocarpo extemo; mt- mesocarpo intemo; ns- núcleo seminífero; sm- semente; st- septo; tr tricoma glandular; wy- fixe vascular ventral. 

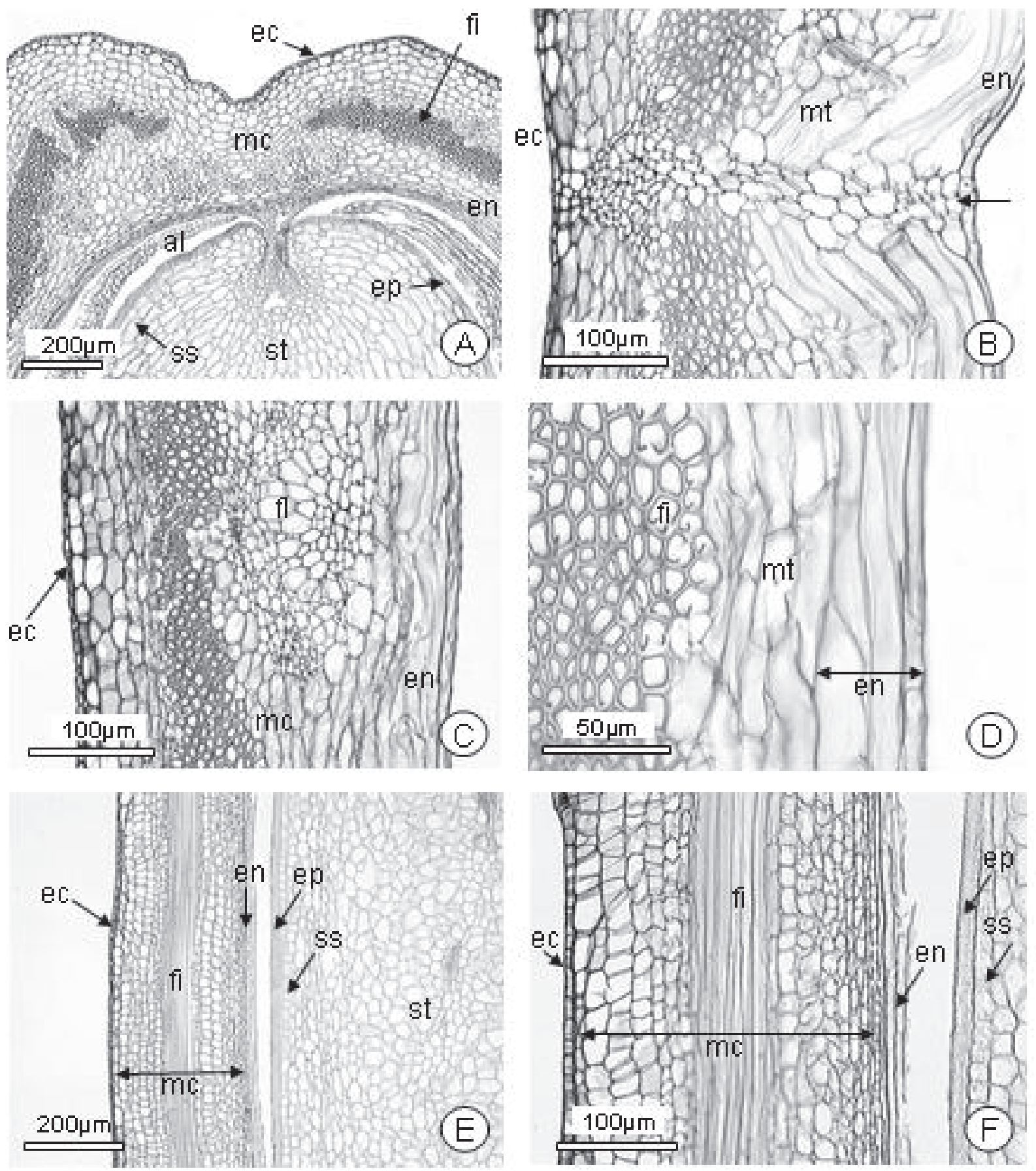

FIGURA 4 - Fruto maduro de Tecoma stans: A - bordo do pericarpo na regăo de inserçăo do septo em secçăo transversal; B - regiăo dorsal do pericarpo em secçăo transversal evidenciando a linha de deiscência (seta); C - regjăo lateral do pericarpo em secçăo transversal evidenciando um feive vascular; D - endocarpo constituído pela epiderme intema do pericarpo e camadas internas do mesofilo em secçăo tranšersal; E - pericarpo e sept em secçăo longitudinal; F pormenor de 4E Legenda: al ala; ec-epicarpo; en- endocarpo; ep- epideme do sep b; fi- fibras; fl- fixe vascular lateral; mc- mesocarpo; mt mesocarpo intemo; pe-pericarpo; ss- camada subepidémmica do septo; st- septo. 

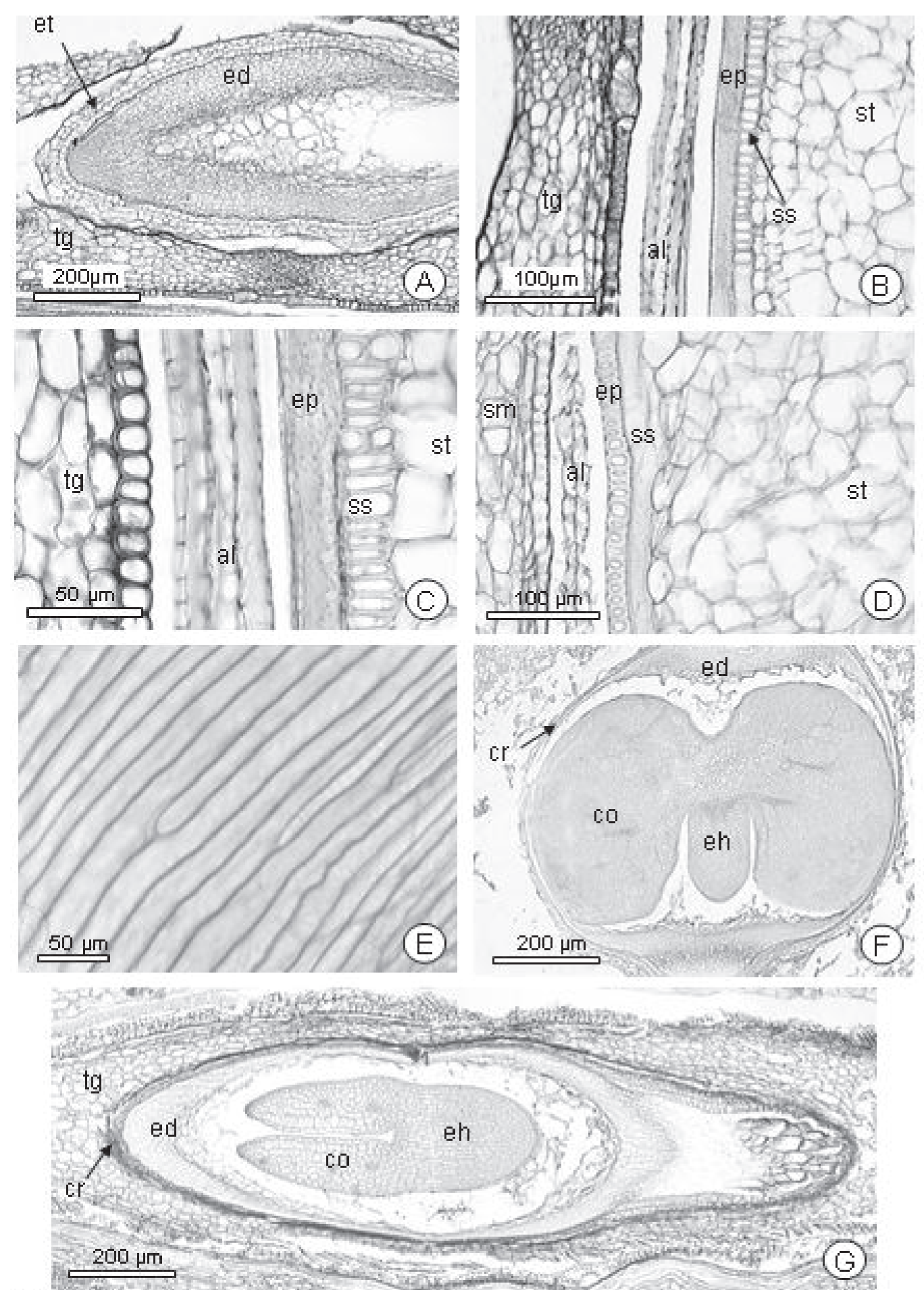

FIGURA 5 - Semente de Tecoma stans: A - endosperma, envoltírio membranáceo e tegumentb em secçăo longitudinal; B - egumento, ala e septo em secçăo longitudinal; C - posmenor de 5B; D - tegumento, ala e septo em secçă transvessal; E - ala em vista frontal; F - embriăo em secçăo longitudinal paralela ao sep b; $\mathrm{G}$-embriăo, endosperma, envoltónio coriáceo e tegumento em secçăo longitudinal perpendicular an septb. Legenda: al ala; co- cotilédone; crenvolb́rio corráceo; ed-endosperma; eh- eixo hipocótilo-radicular; ep- epiderme do septo; et endotélio; sm-semente; ss- camada subepidérmica do septo; st sep b; tg- tegumento. 

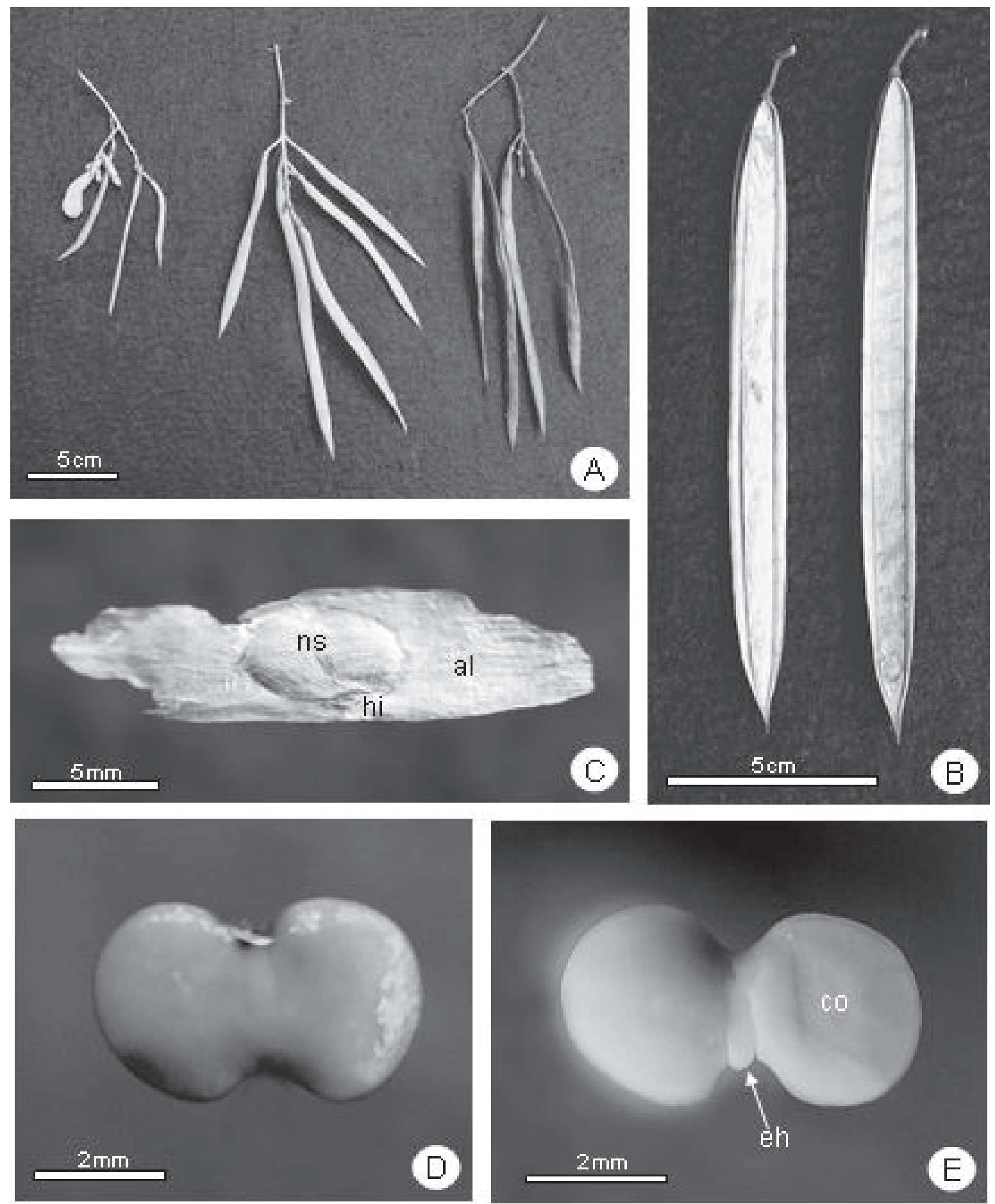

FIGURA 6 - Frub em diferentes estádios, semente e embrăo de Tecoma stans: A - botăo floral, flor, frutos jovens, frutos maduros e frutos em pré-deiscência; B - fruto deiscente com sementes expostas (esquerda) e frub deiscente após a dispersăo das sementes; C - semente alada com núcleo seminífero central, ala e hilo; D embriăo revestido pelo envoltóxio coríceo; E - embrăo isolado evidenciando o eixo hipocótilo-radicular reto e cotilédone bilobado. Legenda: al- ala; cocotilédone; eh-eivo hipocótilo radicular; hi- hilo; ns- núcleo seminífero. 
A estrutura do pericarpo nos estádios iniciais do desenvolvimento é muito semelhante aquela da parede ovariana, ou seja, composta por epicarpo uniestratificado, por um mesocarpo subdividido em três regiões, mesocarpo externo clorofilado com espessura de 10 camadas de células, uma faixa mediana de células precursoras de fibras de esclerênquima e por um mesocarpo interno formado por células parenquimáticas e um endocarpo inicialmente uniestratificado (Figura 2A). As células parenquimáticas do mesocarpo interno, adjacentes ao endocarpo, são alongadas obliquamente e suas paredes são ligeiramente lignificadas (Figuras 4B e 4D). Percorrendo longitudinalmente o mesocarpo, estão distribuídos os feixes vasculares, em ambos os lados da faixa de células precursoras de esclerênquima. Estes feixes, juntamente com a faixa de fibras (Figuras 3A, 3B), são responsáveis pela dureza e deiscência do pericarpo quando maduro (Figuras 4C e 4F) e seco. No epicarpo, ocorrem estômatos ligeiramente salientes e provavelmente funcionais. Segundo Roth (1977) a presença de estômatos em frutos é comum na epiderme externa, podendo ocorrer com menos frequiência na epiderme interna. Porém, em T. stans, não foi observado a presença de estômatos na epiderme interna do pericarpo.

O fruto maduro e deiscente de Tecoma stans é uma cápsula loculicida, pendente, longa, achatada dorsiventralmente, glabra, de coloração verde-amarelada e marrom-ferruginosa quando seca (Figuras 6A e 6B). Neste estádio, após a liberação da semente, observa-se a ruptura do septo na região de inserção com o pericarpo. Esta região é formada por células parenquimáticas (Figura 4A) de pouca resistência mecânica. Em decorrência da degradação natural, o septo é eliminado, restando somente às valvas ligadas a planta.
Kranz e Passini (1997) e Andreazza (2004) consideram o fruto de $T$. stans como síliqua, provavelmente pelo fato de suas sementes permanecerem presas à coluna seminífera ou septo entre duas valvas. Entretanto, de acordo com Barroso et al. (1999), trata-se de cápsula loculicida, pois sua deiscência é perpendicular ao septo, ou seja, na nervura dorsal, sendo cada valva, portanto, formada por metade dos dois carpelos adjacentes. As síliquas, por sua vez, são originadas por deiscência septífraga, ou seja, a linha de deiscência ocorre na região de inserção do septo ao pericarpo, sendo cada valva formada por um carpelo, a placentação é marginal-parietal, encontradas nas famílias Cruciferae (Brassicaceae) e Capparidaceae.

Os frutos secos de $T$. stans presentam na maturidade as dimensões médias de $13 \mathrm{~cm}$ de comprimento, $0,8 \mathrm{~cm}$ de largura e $0,5 \mathrm{~cm}$ de espessura (Tabela 1 ).

\section{MORFO-ANATOMIA DA SEMENTE}

O óvulo em T. stans é anátropo (Figuras 2A, 2B e 2D), unitegumentado e tenuinucelado (Figuras 1B, 2B, 2C e 2D). Nas plantas com flores simpétalas, o nucelo é geralmente envolvido por um único tegumento, enquanto nas dicotiledôneas primitivas e em diversas monocotiledôneas, o óvulo possui dois tegumentos. Durante o desenvolvimento das Angiospermas, a tendência foi a perda de camadas do nucelo, resultando evolutivamente em óvulos anátropos, unitegumentados, tenuinucelados com presença de endotélio e de um endosperma celular (Fahn, 1990). Corner (1976) descreve a família Bignoniaceae constituída por óvulos anátropos ou hemianátropos, unitegumentados e tenuinucelados.

No óvulo de flor em pré-antese, com saco embrionário imaturo, o nucelo é representado pela epiderme nucelar e pela

TABELA 1. Dimensões (cm) dos frutos maduros de Tecoma stans (L.) Kunth

Comprimento

Mínimo

Máximo

Média
6,00

19,55

13,35
Largura

0,63

1,00

0,81
Espessura

0,36

0,72

13,35

0,81 
hipóstase já diferenciada, evidenciada por possuir células com citoplasma denso e paredes espessas, localizada entre a base do saco embrionário a extremidade do feixe funicular (Figuras 2B e 2C). Por esta localização Swamy (1941), citado por Costa (2003), sugere que estas células teriam o papel ativo no transporte de nutrientes para o saco embrionário em desenvolvimento, o que indica a possibilidade de serem células de transferência. Souza et al. (2005) em Tabebuia chrysotricha (Mart. ex A. DC.) Standl. também faz alusões da hipóstase estar relacionada com a poliembrionia. Entretanto esta função da hipóstase não ocorre em T. stans, uma vez que não foi detectada a ocorrência de poliembrionia.

Em T. stans, as sementes desenvolvem-se justapostas e sobrepostas (Figuras 1A, 1B, 2A e 2C) ao longo do comprimento do fruto, ocupando todo o lóculo delimitado pelo septo desenvolvido. São estenospérmicas, exalbuminosas com dois cotilédones foliáceos e bilobados (Figuras 5F e 6E). Ferreira e Cunha (2000), estudando Tabebuia caraiba (Mart.) Bureau, verificaram as mesmas características. Sementes com ausência ou com pequenas quantidades de endosperma (Figuras 5A, 5F e 5G) são referidas como exalbuminosas (Esau, 1974).

Substâncias lipídicas são encontradas nos cotilédones, pericarpo e resquícios endospérmicos.

Durante o desenvolvimento do fruto, as sementes inicialmente globosas (Figura 2A) assumem a forma achatada dorsiventralmente (Figuras 3D, 3E e 6C), acompanhando a forma achatada do pericarpo. As células do tegumento sofrem intensas divisões anticlinais que promovem alongamento da semente, sendo poucas as divisões oblíquas e periclinais. A semente se enquadra como exotestal na classificação de Corner (1976), pois a epiderme externa é a camada mecânica. O tegumento é composto por várias camadas celulares na região do núcleo seminífero (Figuras 5A e 5B), diminuindo gradativamente até tornarse uniestratificada nos bordos.

Com o crescimento do tegumento origina-se a ala (Figuras 3D e 3E). Ala membranácea, formada por células longas (Figura 5E), contendo celulose na região distal e celulose mais lignina na região proximal ao embrião. Assim, a ala da semente madura (Figura 6C) é formada por células epidérmicas, que alongam-se intensamente nas regiões lateral e apical da semente, acompanhando o seu crescimento.
Em T. stans a epiderme interna do tegumento, denominada de endotélio, se destaca do restante do tegumento durante o desenvolvimento da semente e permanece unida com o endosperma adjacente ao tegumento, denominado de endosperma tardio, formando uma estrutura de textura coriácea que irá envolver o embrião (Figuras 5A, 5F, 5G e 6D). Este envoltório coriáceo protege o embrião até a fase de semente madura, quando passa a ter a mesma morfologia do embrião (Figura 6E), completamente separado do restante do tegumento (Figura 5A). Descrição semelhante foi mencionada por Souza et al. (2005) em T. chrysotricha.

Na literatura é comum encontrar citações de ocorrência de endotélio na família Bignoniaceae. Fahn (1990) relata que no óvulo, o endotélio tem função de armazenar grãos de amido. Costa (2003) associa, em Tabebuia ochracea, o endotélio com o endosperma denominando-os de envoltórios membranáceos, provavelmente devido a sua textura menos rígida. No entanto, em T. chrysotricha, descrita por Souza et al. (2005), o endotélio, juntamente com resquícios do endosperma, formam uma camada delgada que envolve o embrião, sem receber dos autores uma denominação especial. Em Pyrostegia venusta (Ker Gawl.) Miers. Gabrielli e Castro (1995) também encontraram estrutura semelhante, denominando-a de tegumento interno.

Os embriões maduros típicos de $T$. stans são representados em sua maior parte pelos cotilédones bilobados (Figura 6E) e justapostos. Embrião reto, espatulado transverso-oblongo, de coloração branca opaca, com eixo hipocotilo-radicular curto, cilíndrico, disposto mediano e verticalmente entre os cotilédones (Figuras 5F e $5 \mathrm{G})$; com plúmula não diferenciada.

A presença do embrião com tecido de reserva, principalmente nos cotilédones, justifica-se em sementes exalbuminosas (Corner, 1976) e são, segundo Cronquist (1988), tipos mais especializados filogeneticamente, uma vez que se acredita que a reserva principal de energia da semente passou do endosperma para o embrião (Von Teichman e Van Wyk, 1994, citado por Costa, 2003). Em T. stans, o endosperma celular restringe-se a vestígios que, juntamente com o endotélio, formam o envoltório já abordado anteriormente (Figuras 5A, 5F e 5G), assim a semente é enquadrada como exalbuminosa. 
TABELA 2. Dimensões (mm) das sementes de Tecoma stans (L.) Kunth

\section{Núcleo seminífero}

\section{Largura total}

\begin{tabular}{lrccc}
\cline { 2 - 4 } & Largura & Comprimento & Espessura & \\
\hline Mínimo & 5,50 & 4,00 & 0,10 & 16,80 \\
Máximo & 8,50 & 6,80 & 0,70 & 30,50 \\
Média & 7,15 & 6,24 & 0,54 & 21,13 \\
\hline
\end{tabular}

Externamente distingue-se na semente o núcleo seminífero ocupando a posição central e a ala que é uma expansão do tegumento. Ala membranácea, hialina e contorna o núcleo seminífero, sendo mais larga que longa (Figuras 3D e 6C). As dimensões do núcleo seminífero da semente madura são: 5,5-8,5mm de largura por 4,0-6,8mm de comprimento e $0,1-0,7 \mathrm{~mm}$ de espessura (Tabela 2).

\section{CONCLUSÕES}

* Tecoma stans possui fruto seco deiscente e do tipo cápsula loculicida.

* O ovário é bicarpelar, biloculado com septo mediano e hemiplacentas com óvulos anátropos, unitegumentados e tenuinucelados.

* A camada espessa de esclerênquima do mesocarpo é um tecido mecânico e participa diretamente na deiscência do fruto.

* A linha de deiscência está preestabelecida desde o início do crescimento do fruto e definida por tecido parenquimático.

* A semente é exalbuminosa, com ala membranácea, composta por células de paredes espessas e celulósicas.

* O embrião, revestido por um envoltório coriáceo, apresenta eixo hipocótilo-radicular curto, reto e cotilédones bilobados, plano-convexos e de reserva lipídica.

\section{REFERÊNCIAS}

ANDREAZZA, C.J. Prospodium appendiculatum (Wint.) Arth. (Uredinales: Pucciniaceae): Perspectivas de utilização no controle biológico de Tecoma stans (L.) Juss. ex. Kunth (Bignoniaceae). In: Princípios e rudimentos do controle biológico de plantas: coletânea. Curitiba: UFPR, 2004. p.161-176.

BARROSO, G.M. Sistemática de angiospermas do Brasil. Viçosa: UFV, 1986. v.3, 326p.

BARROSO, G.M.; MORIM, M.P.; PEIXOTO, A.L.; ICHASO, C.L.F. Frutos e sementes: morfologia aplicada à sistemática de dicotiledôneas. Viçosa: UFV, 1999. 441p.

BITTENCOURT Jr., N.S. Vascularização floral de Tabebuia ochracea (Cham.) Standley (Bignoniaceae). Revista Brasileira de Botânica, São Paulo, v.18, n.2, p.143-155, 1995.

BREDOW, E.A; PEDROSA-MACEDO, J.H.; VITORINO, M.D. Amarelinho Tecoma stans (L.) Jussieu ex. Kunth (Bignoniaceae) uma ornamental multiuso ou uma plástica invasora. In: Princípios e rudimentos do controle biológico de plantas: coletânea. Curitiba: UFPR, 2004. p.51-99.

CORNER, E.J.H. The seed of dicotiledons. London: Cambridge University Press, 1976. v.1,311p.

COSTA, M.E. Morfoanatomia e desenvolvimento do fruto, semente e plântula de Tabebuia ochracea (Chamisso) Standley (Bignoniaceae). Rio Claro, 2003. 109p. Tese (Doutorado em Ciências Biológicas) - Instituto de Biociências, Universidade Estadual Paulista, Rio Claro, 2003.

CRONQUIST, A. The evolution and classification of flowering plants. 2.ed. New York: NYBG, 1988. 555p.

CUTLER, D.F. Apliedt anatomy. London: Longman, 1978. 103p.

DNYANSAGAR, V.R. Embryological studies in the Leguminosae VIII. Acacia auriculaeformeis A. Cunn., Adenanthera pavonina Linn., Calliandra grandiflora Benth. Lloydia, v.21, p.1-25, 1958. 
EAMES, A.J.; MacDANIELS, L.H. An introduction to plant anatomy. New York: McGraw-Hill Book, 1947. 427p.

ESAU, K. Anatomia das plantas com sementes. São Paulo: Edgard Blücher, 1974.293p.

FAHN, A. Plant anatomy. 4.ed. Oxford: Pergamon Press, 1990. $588 \mathrm{p}$.

FERREIRA, R.A; CUNHA, M.C.L. Aspectos morfológicos da semente, plântulas e desenvolvimento da muda de craibeira (Tabebuia caraiba (Mart.) Bur.) - Bignoniaceae e pereiro (Aspidosperma pyrifolium Mart.) - Apocynaceae. Revista Brasileira de Sementes, Brasília, v.22, n.1, p.134-143, 2000.

GABRIELLI, A.C.; CASTRO, M.M. Anatomia da semente madura de Pyrostegia venusta (Ker.) Miers - Bignoniaceae. Revista Brasileira de Botânica, São Paulo, v.18, n.2, p.227-234, 1995.

JOLY, A.B. Botânica: introdução à taxonomia vegetal. 13.ed. São Paulo: Ed. Nacional, 2002.777p.

KRANZ, W.M. Plantas Invasoras no Paraná. In: Princípios e rudimentos do controle biológico de plantas: coletânea. Curitiba: UFPR, 2004. p.43-47.

KRANZ, W. M.; PASSINI, T. Amarelinho - biologia e controle. Informe da Pesquisa, Londrina, v.17, n.121, p.1-19, 1997.

KRAUS, J.E.; ARDUIN, M. Manual básico de métodos em morfologia vegetal. Seropédica: Editora Universidade Rural, 1997. $198 \mathrm{p}$.

LORENZI, H. Plantas ornamentais do Brasil: arbustivas, herbáceas e trepadeiras. 2.ed. Nova Odessa: Instituto Plantarum, 2000. 1088p.
MACHADO, R.S.; GREGÓRIO, E.A.; YANAGIZAWA, Y.; CARMELO, S.M. Ultrastructural aspects of the peltate glandular trichomes of the gynoccium in Zeyheria digitalis (Vell.) Hoehne (Bignoniaceae). Revista Brasileira de Botânica, São Paulo, v.18, n.2, p.197-205, 1995.

PARANÁ. Resolução no 151/97, de 01 de dezembro de 1997. Diário Oficial, Curitiba, 09 de dezembro de 1997. p.17.

RENÓ, L.R. Anatomia da raiz e fenologia de Tecoma stans (L.) Kunth (Bignoniaceae). Maringá, 2002. 36p. Dissertação (Mestrado em Agronomia) - Universidade Estadual de Maringá, Maringá, 2002.

ROTH, I. Fruits of angiosperms. In: LINSBAUER, K. Encyclopedia of plant anatomy. Berlim: Gebrüder Borntraeger, v.10, n.1, p.49-57, 1977.

SASS, J.E. Botanical microtechnique. 2.ed. Ames: Iowa State College Press, 1951. 228p.

SILVA, C.I. Morfo-anatomia, biologia floral e reprodutiva de Tecoma stans (L.) Kunth (Bignoniaceae). Maringá, 2004. 61p. Dissertação (Mestrado em Agronomia) - Universidade Estadual de Maringá, Maringá, 2004.

SOUZA, L.A. Morfologia e anatomia vegetal: célula, tecidos, órgãos e plântula. Ponta Grossa: UEPG, 2003. 258p.

SOUZA, L.A.; IWAZAKI, M.C.; MOSCHETA, I.S. Morphology of the pericarp and seed of Tabebuia chrysotricha (Mart. ex DC.) Standl. (Bignoniaceae). Brazilian Archives of Biology and Technology, Curitiba, v.48, n.3, p.407-18, 2005. 